Original Article

\title{
Endovascular Embolization of Facial Artery Pseudoaneurysm following Lancing of a Subperiosteal Abscess: Case Report ${ }^{\star}$
}

\author{
Andrii S. Hresko1, Denys M. Chernohorskyi², Sergey V. Vereshchagin ${ }^{3}$, and Andrii V. Kopchak 4,* \\ ${ }^{1}$ Center of Maxillofacial Surgery \& Dentistry, Department of Stomatology, Bogomolets National Medical University, Kyiv Regional \\ Clinical Hospital, Kyiv, Ukraine (Clinical Ordinator) \\ ${ }^{2}$ Center of Maxillofacial Surgery \& Dentistry, Department of Stomatology, Bogomolets National Medical University, Kyiv Regional \\ Clinical Hospital, Kyiv, Ukraine (PhD Student) \\ ${ }^{3}$ Center of Vascular \& Cardioendovascular Surgery, Kyiv Regional Clinical Hospital, Kyiv, Ukraine $(P h D)$ \\ ${ }^{4}$ Center of Maxillofacial Surgery \& Dentistry, Department of Stomatology, Bogomolets National Medical University, Kyiv Regional \\ Clinical Hospital, Kyiv, Ukraine (ScD, Prof)
}

\author{
ABOUT ARTICLE \\ Article history: \\ Paper received 18 January 2019 \\ Accepted 28 January 2019 \\ Available online 31 January 2019 \\ Keywords: \\ Facial artery pseudoaneurysm \\ Pseudoaneurysm \\ False aneurysm \\ Pulsating hematoma \\ Facial artery embolization \\ Angiography
}

\begin{abstract}
S U M M A R Y
Pseudoaneurysms of the facial artery are the rare complications of traumatic injuries and surgical interventions in the area of head and neck. One of the vessels of the external carotid system, which suffers from this pathology most frequently, is the facial artery. The article describes a clinical case of the facial artery pseudoaneurysm, which was formed as a result of subperiosteal abscess lancing (synonym: periosteotomy) performed in the area of a tooth \#36. The features of the clinical picture, diagnostic algorithms and the choice of treatment approach in such cases are discussed. The successful experience of angiography application and endovascular embolization of the facial artery in this patient is presented.
\end{abstract}

(C) 2019 OMF Publishing, LLC. This is an open access article under the CC BY licence (http://creativecommons.org/licenses/by-nc/4.0/).

\section{Introduction}

Aneurysm of the external carotid artery and its branches is rare pathological condition which is a major challenge for the maxillofacial surgeons, either for diagnostics or treatment. In the literature, all vascular aneurysms are classified into true and false types. True aneurysms are localized, abnormal dilations of arteries caused by a weakening of their walls and containing all three layers (tunica intima, media and adventitia). They are usually associated with atherosclerosis, congenital structural weakness, syphilis, and mycotic infections.

Pseudoaneurysm (false aneurysm or pulsating hematoma), on the contrary, is a traumatic vascular injury resulting from a laceration/rupture of the arterial

\footnotetext{
* This manuscript has not been presented

* Corresponding author. Department of Stomatology, Institute of Postgraduate Education, Bogomolets National Medical University, 1, Zoolohichna Street, Kyiv, 04119, Ukraine.

Ukraine.
Tel.: +38 (067) 4099037.

E-mail address: kopchak@ua.fm (Andrii V. Kopchak)

http://dx.doi.org/10.23999/j.dtomp.2019.1.6.
}

wall with blood extravasation into surrounding tissues. The wall of the pseudoaneurysm consists of perivascular fibrous tissue, which forms the blood-filled or clot-filled sac into which arterial blood continues to flow. After the blunt or penetrating trauma with partial arterial wall injury the extravasation into the surrounding tissues continues until the pressure inside the hematoma equals the arterial pressure, followed by tamponade and clot formation. The lesion which occurs may be bounded by outer layers of a partially disrupted artery, muscle, fascia or skin surfaces, or by a fibrous, well-organized wall, depending on the location of the pseudoaneurysm and duration of the process [1]. Within weeks, the hematoma inside the sac begins to liquefy, producing a cavity lined by endothelium. A communication between the artery and the aneurysmal cavity develops, the mass begins to pulsate, and progressively enlarge. Pseudoaneurysm may gradually expand and rupture, leading to life threatening hemorrhage [2]. If a developing aneurysm is covered by a strong fascial layer, it tends to develop slowly. However, if it is covered with the lax tissues covering, it tends to grow more rapidly [3].

Pseudoaneurysms are relatively rare in the 
maxillofacial area, because trauma to external carotid artery branches usually results in total transection rather than in partial laceration of blood vessel due to their small caliber [4]. Most affected vessels are the superficial temporal artery, internal maxillary artery and facial artery, usually where the vessels approach the surface to cross bone structures (zygomatic bone or mandible). In these areas they become especially vulnerable to the blunt trauma. The false aneurysms arise most frequently in the superficial temporal artery $[5,6]$. Of the 386 cases of facial aneurysm reported in the world literature, 327 involve the superficial temporal artery. However the other branches of the external carotid artery are sometimes involved, including the facial artery. The injury of the facial artery is determined by its anatomic location and lack of dense fascial spaces in the area, where it cross the inferior border of the mandible, immediately in front of the masseter and passes upward toward the angle of the mouth. Due to that the distal segments of facial artery give rise to pseudoaneurysms in most of the patients and only a few cases of proximal parts affection (from external carotid artery up to the lower border of the mandible) are reported in the literature.

Facial pseudoaneurysms are usually caused by blunt trauma [7-9] or high-velocity penetrating injuries [10-15], gunshot or knife wounds [16]. However iatrogenic injuries have been also reported as causes of facial pseudoaneurysms. The authors observed pseudoaneurysms development after tonsillectomy [17], surgical removal of molar teeth [18], reduction and osteosynthesis of fractured facial bones [19, 20], circummandibular wiring [21], neck dissection [22-24], orthognathic surgery [Le Fort I osteotomies [25], bilateral sagittal split osteotomies (BSSO), mandibular vertical ramus osteotomy, and temporomandibular joint surgery] $[27,15,28]$. Infection, radiotherapy, poor nutrition, and malignancy are considered as predisposing factors for the lesion development $[29,30]$.

Diagnosis of a pseudoaneurysm is mainly based on clinical examination. Physical findings are pulsating mass, pain, associated palpable thrill, systolic bruit during auscultation or unexplained neurological deficits [19]. A superficial aneurysm is typically detected from few weeks to 4 months after trauma. In the traumatized area a painful mass can be noted, resulting in adjacent soft-tissue deformity. The overlying skin is often discolored. Due to the delayed appearance of the aneurysm, patients may not associate trauma with the lesion. With liquefaction of the lesion content, a systolic bruit and pulsation may develop, and signs of fluctuation may be find out in some cases. This would depend on the anatomic location of the injured artery as well as the nature of the covering tissues. In clinical examination digital pressure proximal to the lesion may stop the pulsation.

Imaging is important to define the localization and extent of the lesion. Color Doppler ultrasonography has been suggested as a screening method by Nadig et al
(2009) [24] and contrast CT or angiography confirms the diagnosis.

The diagnosis of pseudoaneurysm on color Doppler ultrasound is made by demonstration of a sac with turbulent flow outside the lumen of the associated vessel [32]. Contrast enhanced CT defines the actual dimensions of the lesion, its relation to surrounding structures as well as a degree of a possible thrombosis [33], but may not clearly show the vascular abnormalities in partially developed pseudoaneurysms. Thus, angiography becomes an essential tool to confirm the diagnosis [18]. However, the final diagnosis of pseudoaneurysm is made by the pathologist, who can microscopically distinguish true from false aneurysm, depending on the layers of the vessel wall involved [34].

Treatment of false aneurysms is generally considered mandatory because of the unstable wall and possibility of spontaneous expansion and rupture. Many different methods for treating pseudoaneurysms have been described in the literature. They include observation, compression, anticoagulation, ligation and surgical removal or endovascular embolization/stenting [23].

Many authors consider that pseudoaneurysms of the external carotid artery and its branches are best treated with surgical isolation and ligation of vessels supplying the false aneurysm, with or without excision of the mass. Reconstruction of the vessel is usually not necessary in the head and neck where the multiple collaterals and anastomoses are present [28]. Due to that, there are no consequences to tissue perfusion with ligation of the external carotid artery brunches and the risk of perioperative complications is minimal.

More recently, however, advances in interventional radiology allowed successful treatment of false aneurysms using endovascular embolization performed in conjunction with angiography [35]. Method utilizes materials that occlude the vessel, either temporarily or permanently, resulting in conversion of the pseudoaneurysm into a hematoma, which then resorbs over time. Metallic coils, polyvinyl alcohol particles, and absorbable gelatin sponge are the most common embolic agents. Iso-cyanoacrylate and bovine thrombin are used less frequently [27, 36, 37]. These techniques are particularly useful for aneurysms for which surgical accessibility is difficult.

The present article gives an evidence of successful diagnostics and treatment of iatrogenic pseudoaneurysm of the facial artery with endovascular embolization, performed under control of digital subtraction angiography.

\section{Case Report}

A 32-years-old male patient complaining on swelling at the left buccal area and periodical bleeding from the oral cavity up to $2 \mathrm{ml}$ was examined in the Center of Maxillofacial Surgery, Kyiv Regional Clinical Hospital. 2 months ago patient underwent the extraction of tooth 36 
for periapical lesion. In the postextraction period infection developed with the signs of alveolitis and subperiosteal abscess in the area of extracted tooth. In 5 days the abscess was incised intraoraly and drained in oral surgery outpatient clinic. After 7 days of antibiotic treatment the patient was better and the swelling subsided, but did not totally disappear. From anamnesis it was find out that the swelling periodically increased in size with some episodes of intensive bleeding to the oral cavity after long-time articulation or mastication of the hard food. The bleeding stopped spontaneously or by application of hydrogen peroxide soaked gauze. Clinical examination revealed a movable painless swelling, located in the lower part of the left buccal area. The overlying skin was intact with no signs of hyperemia. The size of the lesion was about $3 \times 2$ $\mathrm{cm}$. No signs of pulsation or systolic bruit were observed. Intraoral examination revealed periosteotomy area.

As the tumor was initially suspected, patient was referred for an ultrasound of the left submandibular and cheek areas and angiography before the definite diagnosis. The ultrasound revealed the oval shape anechoic vascular mass with distinct boundaries, equal contours and the blood flow in the central area of the lesion (determined by Color Doppler ultrasound).

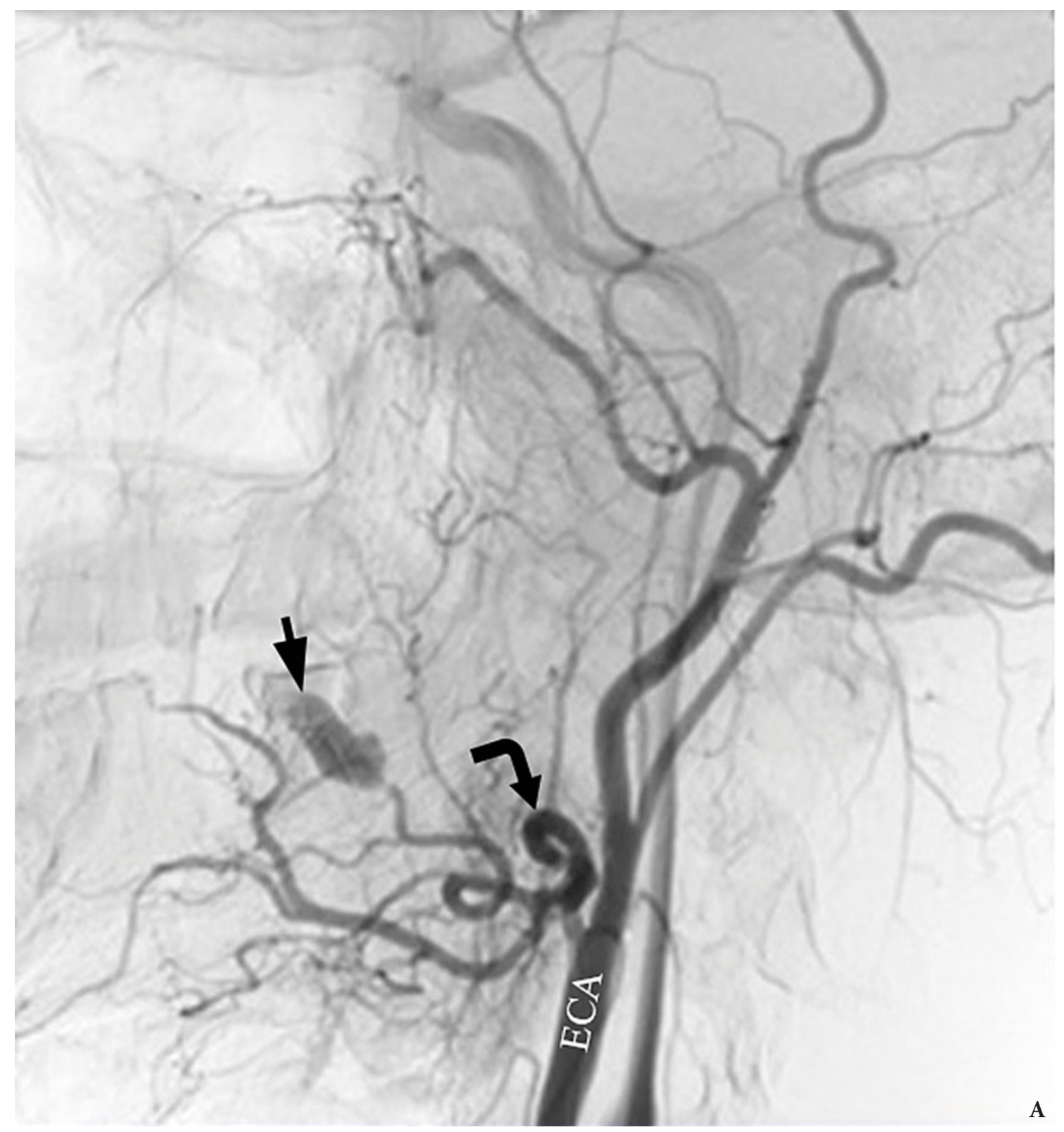

FIGURE 1. (A) Angiography of the left external carotid artery (letters ECA), presenting the vascular lesion-pseudoaneurysm (arrow) connected to the left facial artery (curved arrow) (Fig 1 continued on next page.). 


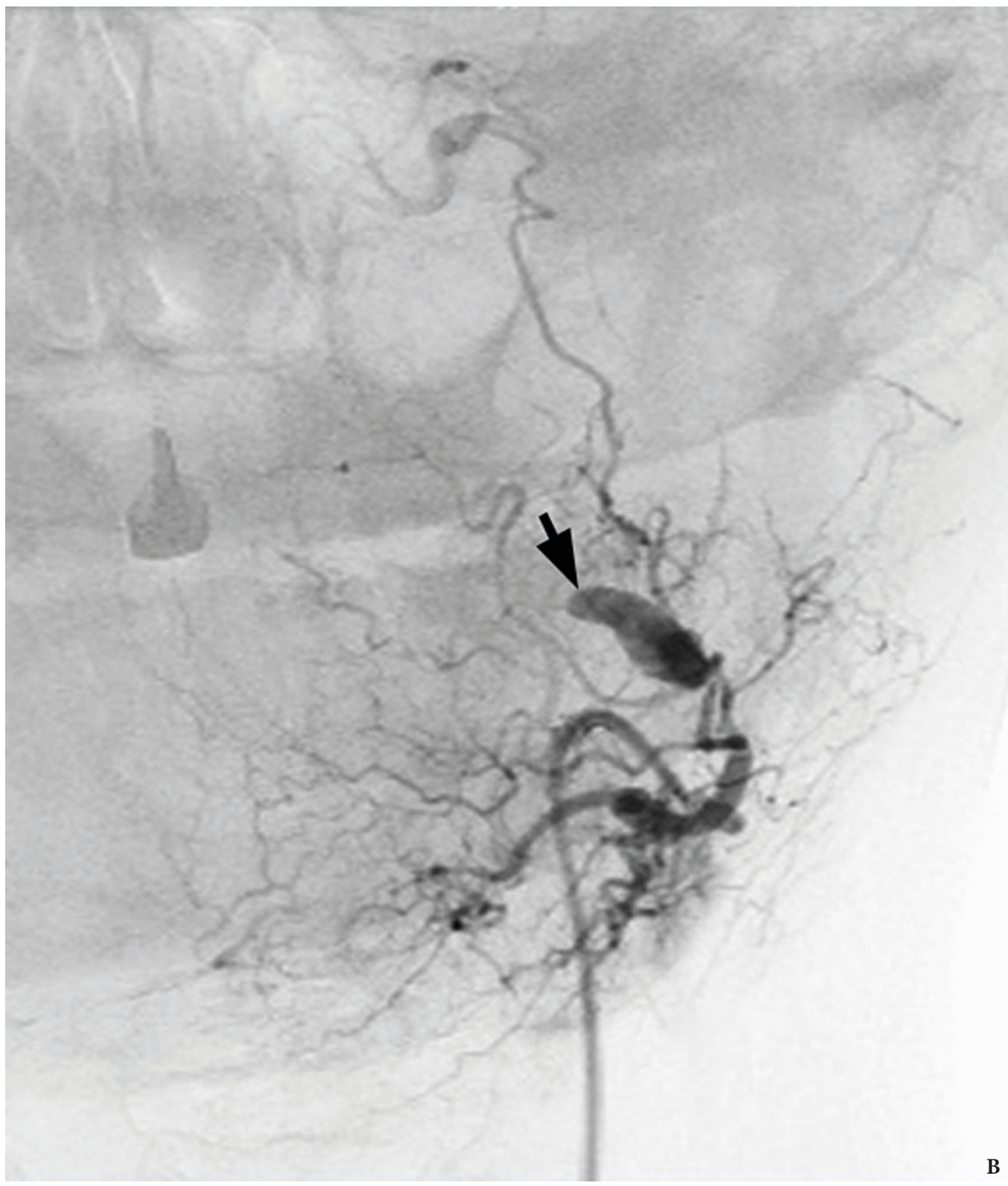

FIGURE 1 (cont'd). (B) Angiography of the left external carotid artery, presenting the vascular lesion-pseudoaneurysm (arrow) connected to the left facial artery.

The present findings supported the diagnosis of aneurism or pseudoaneurysm of the left facial artery or one of its branches. Laboratory tests of the patient were within the normal limits.

After consulting a vascular surgeon it was decided to perform a selective arteriography (Fig 1) of the external carotid artery with immediate endovascular embolization/ stenting of the left facial artery. Under the local anesthesia, by Seldinger approach, through the right femoral artery ( $6 f$ introducer), a $5 \mathrm{f}$ catheter (headhunter type) was inserted to the left external carotid artery. The angiography revealed an oval lesion $13 \times 5 \mathrm{~mm}$. Most of it intensively accumulated the contrast only some peripheral areas were filled with thrombotic masses. This lesion was connected to the left facial artery with visible continuity of the contrast inside the vessel and inside the lesion. Such findings confirmed the diagnosis of facial artery pseudoaneurysm. A catheter was further moved to the facial artery and embolization was performed using polyurethane foam d $200 \mu \mathrm{m}+$ spiral "Tornado" (cook) d 3/4 mm (Fig 2A, B). 


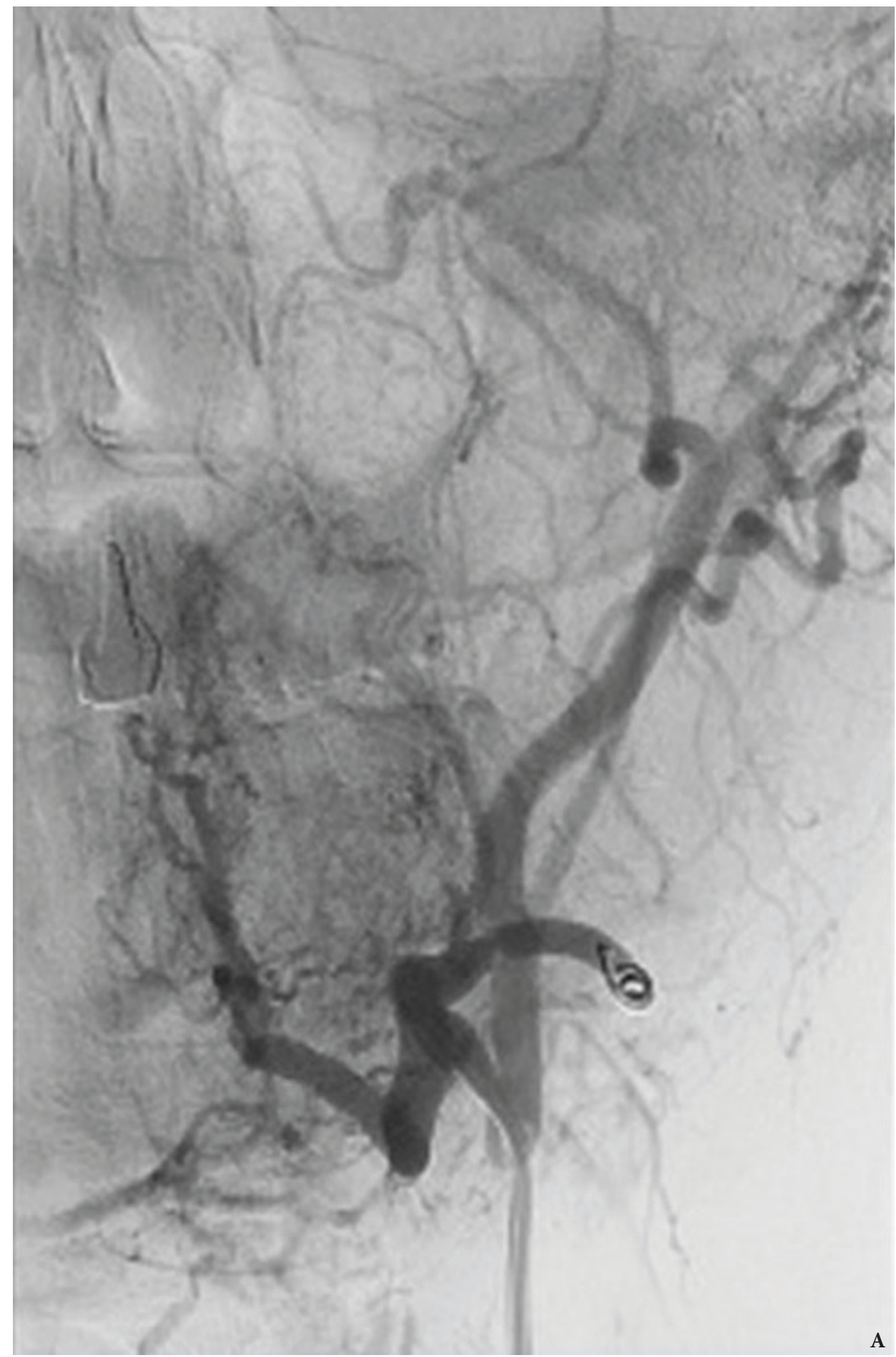

FIGURE 2. Embolization of the left facial artery. The control scans $(\mathbf{A}, \mathbf{B})$ shows that facial artery is blocked with no signs of contrast accumulation inside the aneurysm (Fig 2 continued on next page.). 


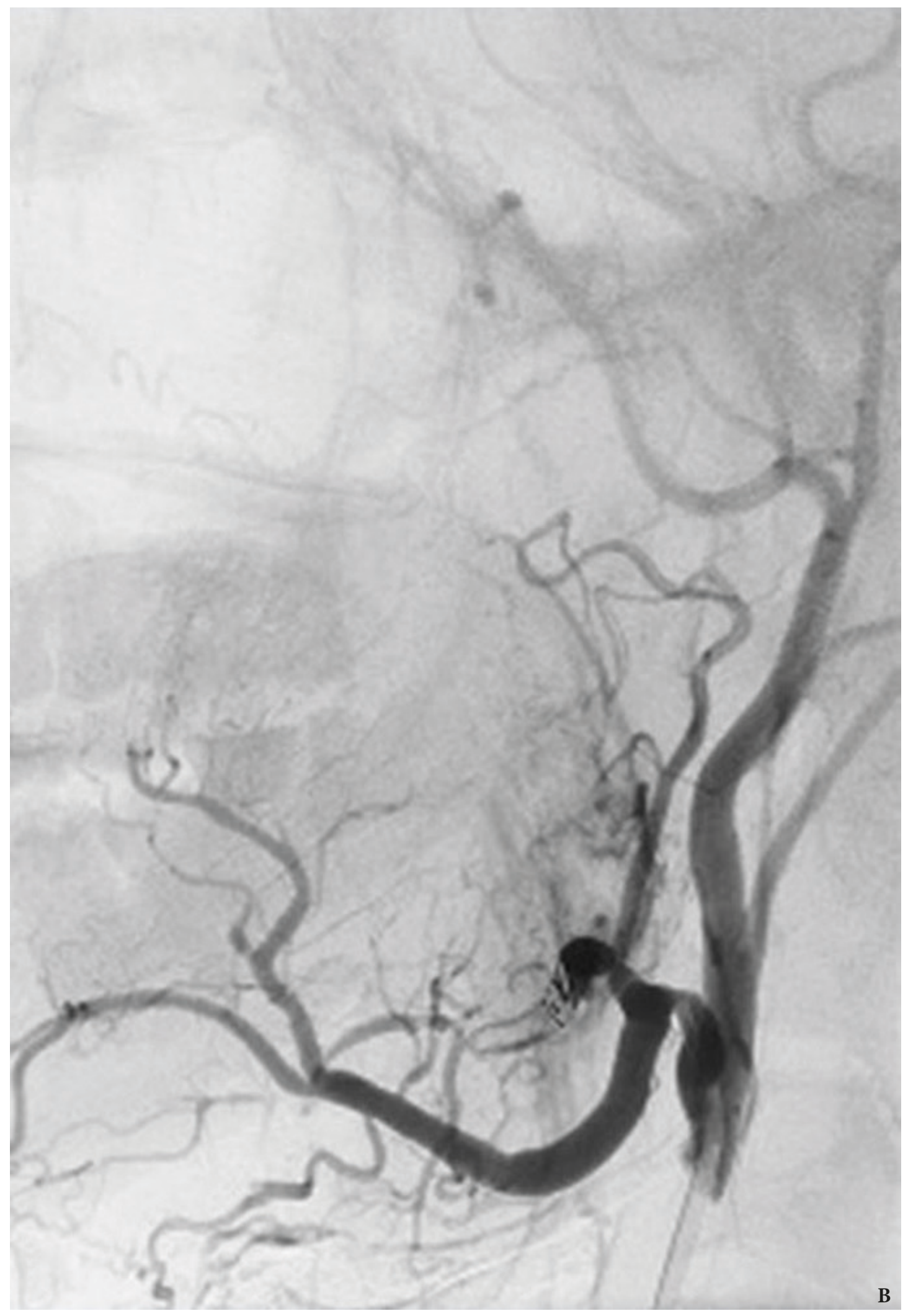

FIGURE 2 (cont'd). Embolization of the left facial artery. The control scans $(\mathbf{A}, \mathbf{B})$ shows that facial artery is blocked with no signs of contrast accumulation inside the aneurysm. 
The control scan showed that facial artery was blocked and no signs of contrast accumulation inside the aneurysm were found. Introducer and catheter were removed. Pressing bandage was applied after hemostasis.

No complications were observed in postoperative period, and the patient was discharged home on the third day after procedure. In 10 days follow up were observed.

\section{Discussion}

The present clinical case demonstrates the rare form of the vascular pathology with maxillofacial localization pseudoaneurysm of the facial artery, with only 26 cases documented in open literary sources [11]. In our case the pseudoaneurysm resulted from arterial wall injury after incision and draining of the subperiosteal abscess in the molar area of the mandible. Such iatrogenic cause of the lesion is quite uncommon, although reported the case a facial aneurism resulted from mandibular vertical ramus osteotomy. Another case was presented by Rayati et al (2010) where pseudoaneurysm of the facial artery developed after tooth extraction [18].

Authors reported that the posttraumatic pseudoaneurysm usually presents several days or weeks after the injury [38] as it was in the present case where the final diagnosis and definite treatment were performed after 2 months from injury and first clinical manifestations. The case was hard for diagnostics, but the clinical signs of the pseudoaneurysm and periodic bleeding suppose the presence of the vascular lesion, confirmed by the ultrasonic and radiological examination. Clinical findings such as bruit and pulsations which suggest a vascular nature of the lesion and its association with arterial vessels are not always seen in cases of the pseudoaneurysms of the external carotid branches as it was in present case. It complicates the differential diagnosis and determines the necessity of additional diagnostic procedures, such as ultrasound or angiography.

The present case support the evidence that color Doppler ultrasound is an adequate quick and cost-effective method which make it possible to confirm the diagnosis of pseudoaneurysm and to choose an appropriate therapeutic approach. However it provides less detail and may be limited by bone structures; sometimes it may be also associated with clot displacement and rapture of the lesion during the examination [15].

To confirm the diagnosis and to get more detailed information about the location and trough dimensions of lesion, its topography, relation to surrounding structures and association with certain artery the contrast CT or digital subtractive angiography should be used.

The indications for the surgical treatment it the present case were quite obvious. The presence of bleeding and its intensity as well as the possibility of expansion and rupture of the aneurysm wall indicated that such lesion should be removed or obliterated obligatory, and conservative approach (observation of the process dynamics or sclerotherapy) could not be considered as adequate. In our case the endovascular treatment was successfully applied for the treatment of the facial artery pseudoaneurysm with following benefits: the improved diagnostics and precise determination of the injured artery, the possibility to block the vessel by embolization under the visual control and to check the effectiveness of the procedure afterwards. In the similar case Dediol et al (2011) advocated the surgical management as a treatment of choice for facial pseudoaneurysm [34]. His concept is mainly based on the evidence that there are no consequences to tissue perfusion with ligation of external carotid artery branches and the risk of perioperative complications is minimal. De Vogelaere (2004) studied his case of pseudoaneurysm involving superficial temporal artery and considered surgical resection as definitive management as it eliminates the risk of spontaneous rupture and hemorrhage [39]. However the decision making depends on the location and accessibility of the area.

In our case the endovascular technique used for the facial pseudoaneurysm management had significant benefits compared to the open surgery. It make it possible to avoid the extraoral excisions and the scars on the face, decrease the risk of facial nerve (marginal branch) injury, and was important for definite diagnostics as the injured branch of the external carotid artery was not detected clearly by the ultrasonic examination. Risks of embolization include cerebrovascular accidents secondary to embolization from the great vessels and autolysis of the embolization material over time but such complications are very rare in clinical practice [15].

The endovascular approach at the same time limits the possibilities of the pathohystologic examination which is necessary to distinguish the true aneurism and pseudo aneurysm depending on the layers of the vessel wall involved. However, in our case with young patient, no signs of systemic vascular pathology and atherosclerosis and presence of the surgical trauma in anamnesis such differential diagnosis was not mandatory and it did not influence the treatment strategy.

Thus pseudoaneurysm of the facial area is a rare condition that should be always considered in the differential diagnosis of the soft tissue lesions in the areas adjacent to the artery location. As it may arise after surgical manipulations, such possibility should be also taken into consideration by oral surgeons. Aneurysms may be injured accidentally and easily ruptured, with the possibility of the patient hemorrhaging, and it makes the proper diagnostics and adequate management essentially important however it could be quite complicated and require the additional diagnostics procedures. Color Doppler ultrasound and carotid angiography are the main procedures used for definite diagnostics and treatment planning. There are a lot of treatment options discussed in the literature which include excision, ligation, and arterial embolization; all of them provided pretty good results in 
cases reported. Our observation give an evidence of the successful treatment of facial artery pseudoaneurysm with endovascular embolization, performed under control of digital subtraction angiography. The main benefits of the technique were high precision and minimal invasiveness of the technique.

\section{Role of the Co-authors}

The authors are equally contributed to that article. All authors read and approved the final manuscript.

\section{Term of Consent}

No needed.

\section{Fundings}

No funding was received for this study.

\section{Acknowledgments}

None.

\section{References}

1. Dunphy JE, Way LW. Current surgical diagnosis and treatment. 5th ed. Los Angeles: Lange Medical Publications; 1981.

2. Rich NM, Spencer FC. Vascular trauma. Philadelphia: WB Saunders; 1978.

3. O'Brian CE. An unusual complication following facial trauma. Int J Oral Surgery 1981;10(suppl):241.

4. Germiller JA, Myers LL, Harris MO, Bradford CR. Pseudoaneurysm of the proximal facial artery presenting as oropharyngeal hemorrhage. Head Neck 2001;23(3):259-63.

5. Ferris EJ, Shapiro JH, Roth DA, Bub B. Superficial temporal artery aneurysms. Radiology 1967;88(2):268-70. https:// doi.org/10.1148/88.2.268.

6. Petitti L, Jennings HB Jr. False aneurysm of the facial artery. US Armed Forces Med J 1952;3(5):781-4.

7. Gerbino G, Roccia F, Grosso M, Regge D. Pseudoaneurysm of the internal maxillary artery and Frey's syndrome after blunt facial trauma. J Oral Maxillofacial Surgery 1997;55(12):1485-90.

8. Golden GT, Fox JW, Williams GS, Edgerton MT. Traumatic aneurysm of the superficial temporal artery. Squash-ball disease. JAMA 1975;234(5):517-8.

9. Krishnan DG, Marashi A, Malik A. Pseudoaneurysm of internal maxillary artery secondary to gunshot wound managed by endovascular technique. J Oral Maxillofac Surg 2004;62(4):500-2.

10. Kennedy JW, Kent JN. False aneurysm and partial facial paralysis secondary to mandibular fracture. J Oral Surgery 1970;28:854-6.

11. Conner WCIII, Rohrich RJ, PollockRA. Traumaticaneurysms of the face and temple: a patient report and literature review, 1644 to 1998. Ann Plastic Surgery 1998;41(3):321-6.

12. Amirjamshidi A, Abbassioun K, Rahmat HR. Traumatic aneurysms and arteriovenous fistulas of the extracranial vessels in war injuries. Surg Neurol 2000;53(2):136-45.

13. Ramsay DW, McAuliffe W. Traumatic pseudoaneurysm and high flow arteriovenous fistula involving internal jugular vein and common carotid artery. Treatment with covered stent and embolization. Australas Radiol 2003;47(2):177-80.

14. Martinod E, Warnier G, Aupecle B, Lajos P, Chapuis O, Pons F, Azorin JF, Jancovici R. False aneurysm of the left common carotid artery 52 years after penetrating injury of the chest. J Trauma 1999;47(2):400-2.

15. Ali ZA, Malis DD, Wilson JW. Pseudoaneurysm of the maxillary artery after a stab wound treated by endovascular embolization. J Oral Maxillofac Surg 2007;65(4):790-4. https://doi.org/10.1016/j.joms.2005.11.070.

16. Banks P, Redpath. Closed carotid artery hemorrhage as a complication of minor gunshot wounds of the face and jaws. J Oral Surgery 1972;30(3):176-83.

17. Karas DE, Sawin RS, Sie KC. Pseudoaneursym of the external carotid artery after tonsillectomy. A rare complication. Arch Otolaryngol Head Neck Surg 1997;123(3):345-7.

18. Rayati F, Parsa H, Abed PF, Karagah T. Facial artery pseudoaneurysm following surgical removal of a mandibular molar. J Oral Maxillofacial Surgery 2010;68:1683-5. https:// doi.org/10.1016/j.joms.2009.07.078.

19. El AS, Guo W, Loveless T, Dhaliwal SS, Quereshy FA, Baur DA, Kaka NS. Pseudoaneurysm of the external carotid artery secondary to subcondylar fracture. Int $J$ Oral Maxillofacial Surgery 2011;40(6):644-6. https://doi. org/10.1016/j.ijom.2010.11.022.

20. Zachariades N, Skoura C, Mezitis M. Marouan S. Pseudoaneurysm after a routine transbuccal approach for bone screw placement. J Oral Maxillofacial Surgery 2000;58(5):671-3.

21. van den Akker HP, van den Lijn F. A false aneurysm of the facial artery as a complication of circumferential wiring. $J$ Oral Surgery 1974;37(4):514-7.

22. Minion DJ, Lynch TG, Baxter BT, Lieberman R. Pseudoaneurysm of the external carotid artery following radical neck dissection and irradiation - case report and review of the literature. Cardiovasc Surg 1994;2(5):607-11.

23. Nadig S, Barnwell S, Wax MK. Pseudoaneurysm of the external carotid artery-review of literature. Head Neck 2009;31(1):136-9.

24. Kraus RR, Bergstein JM, DeBord JR. Diagnosis, treatment and outcome of blunt carotid arterial injuries. Am J Surg 1999;178(3):190-3.

25. Lanigan DT, Hey JH, West RA. Major vascular complications of orthognathic surgery: hemorrhage associated with Le Fort I osteotomies. J Oral Maxillofac Surg 1990;48(6):561-73.

26. Lanigan DT, Hey JV, West RA. Major vascular complications of orthognathic surgery: false aneurysms and arteriovenous fistulas following orthognathic surgery. J Oral Maxillofac Surg 1991;49(6):571-7.

27. Clark R, Lew D, Giyanani VL, Gerlock A. False aneurysm complicating orthognathic surgery. J Oral Maxillofac Surg 1987;45(1):57-9. https://doi.org/10.1016/02782391(87)90087-5

28. Kornbrot A, Shaw AS, Toohey MR. Pseudoaneurysm as a complication of arthroscopy. A case report. J Oral Maxillofacial Surg 1991;49(11):1226-8

29. Rich NM, Hobson RW, Collins GJ. Traumatic arteriovenous fistulas and false aneurysms: a review of 558 lesions. Surgery 1975;78(6):817-28.

30. Hertzer NR. Extracranial carotid aneurysms: a new look at 
an old problem. J Vasc Surg 2000;31(4):823-5. https://doi. org/10.1016/10.1067/mva.2000.105675.

31. Yuen JC, Gray DJ. Endovascular treatment of a pseudoaneurysm of a recipient external carotid artery following radiation and free tissue transfer. Ann Plast Surg 2000;44:656-9.

32. Partridge E, Zwirewich CV, Salvian AJ. Facial artery pseudoaneurysm: diagnosis by colour Doppler ultrasonography. J Can Assoc Radiol 1995;46(6):458-60.

33. Marco de Lucas E, Gutiérrez A, González Mandly A, García-Pire F, Marco de Lucas MT, Parra JA, Sáiz-Bustillo R. Life-threatening pseudoaneurysm of the facial artery after dental extraction: successful treatment with emergent endovascular embolization. Oral Surg Oral Med Oral Pathol Oral Radiol Endod 2008;106(1):129-32. https://doi. org/10.1016/j.tripleo.2007.09.031.

34. Dediol E, Manojlovic S, Biocic J, Franceski D, Ivanac G. Facial artery pseudoaneurysm without evidence of trauma.
Int J Oral Maxillofac Surg 2011;40(9):988-90. https://doi. org/10.1016/j.ijom.2011.03.010.

35. Ditmars ML, Klien SR, Bongard F. Diagnosis and management of zone III carotid injuries. Injury 1997;28(8):515-20.

36. Zachariades N, Rallis G, Papademetrious $P$, et al. Embolization for the treatment of pseudoaneurysm and transaction of facial vessels. Oral Surg Oral Med Oral Pathol Oral Radiol Endod 2001;92:491-4.

37. Peoples JR 3rd, Herbosa EG, Dion J. Management of internal maxillary artery hemorrhage from temporomandibular joint surgery via selective embolization. J Oral Maxillofac Surg 1988;46(11):1005-7.

38. Feliciano DV, Cruse PA, Burch JM, Bitondo CG. Delayed diagnosis of arterial injuries. Am J Surg 1987;154(6):57984. https://doi.org/10.1016/0002-9610(87)90220-0

39. De Vogelaere K. Traumatic aneurysm of the superficial temporal artery - case report. J Trauma 2004;57(2):399-401. 